\title{
Hieracium elisaeanum Arv.-Touv. ex Willk. (Asteraceae), novedad para la flora de Andalucía Occidental (España)
}

\section{Gonzalo Mateo ${ }^{1} \&$ Juan Antonio Devesa ${ }^{2}$}

1Jardín Botánico. Universidad de Valencia. C/ Quart, 80. 46008 Valencia (España).

²Departamento de Botánica, Ecología y Fisiología Vegetal, Facultad de Ciencias, Universidad de Córdoba. Edificio José Celestino Mutis, Campus de Rabanales, Universidad de Córdoba, 14071 Córdoba (España).

\section{Correspondencia}

Juan Antonio Devesa

e-mail: bv1dealj@uco.es

Recibido: 16 octubre 2020

Aceptado: 26 octubre 2020

Publicado on-line: 12 noviembre 2020

Editado por: Marta Recio Criado

\begin{abstract}
Resumen
Se da a conocer por primera vez la presencia en la provincia de Córdoba de Hieracium elisaeanum Arv.-Touv. ex Willk., novedad también para la flora de Andalucía Occidental.
\end{abstract}

Palabras clave: Flora vascular, Córdoba, Corología, Hieracium

\begin{abstract}
Hieracium elisaeanum Arv.-Touv. ex Willk. (Asteraceae), novelty for the flora of Western Andalusia (Spain)

The presence of Hieracium elisaeanum Arv.-Touv. ex Willk. in the province of Cordoba is reported for the first time, and this new record supports its inclusion in the flora of western Andalusia.
\end{abstract}

Keywords: Vascular flora, Cordoba, Chorology, Hieracium.
Hieracium elisaeanum Arv.-Touv. ex Willk.,Suppl. Prodr. FI. Hisp.: 120 (1893)

ESPAÑA. Córdoba: Priego de Córdoba, La Tiñosa, 30SUG9038, 6-VII-1983, F. Infante \& J.M. Muñoz (COFC 70795)

El género Hieracium L. ha sido objeto de recientes estudios monográficos (Mateo et al., 2017; Mateo et del Egido, 2017), que muestran su abultada participación en la flora española aunque con grandes asimetrías entre las partes septentrionales y meridionales de la Península Ibérica; muchas especies en el norte (más de 100 en provincias como las de León, Huesca o Gerona), una representación moderada en el centro (c. 50 especies en provincias como las de Guadalajara, Soria o Teruel) y mucho más escasa en el sur. En este último caso, en lo que concierne a Andalucía, destacar que la mayor diversidad de especies se localiza en las provincias de su mitad oriental -sobre todo Almería, Granada y Jaén-, para las que se han reconocido 8 especies (Blanca \& Cueto, 2011), mientras que para la mitad occidental solo se reconoce la presencia de Hieracium baeticum Arv.-Touv. \& Reverchon (cf. Talavera, 1987), en la actua-lidad considerado como un híbrido entre tres especies (Mateo et al., 2017).

\section{Taxonomía}

Al revisar materiales sin identificar en el herbario COFC, se detectaron unos ejemplares de Hieracium en la provincia de Córdoba que han sido finalmente identificados como H. elisaeanum Arv.-Touv. ex Willk. Se trata de un endemismo iberolevantino descrito de las sierras de Javalambre -Teruel- y de Castalla -Alicante- (cf. Willkomm, 1893) que extiende su área desde la Sierra de Cantabria -sur de Álava y Navarra- hasta la provincia de Almería (cf. ArvetTouvet, 1913: 180, sub $H$. almerianum) y el resto de Andalucía Oriental, con muy buena representación en la Cordillera Ibérica (Cs Cu Gu Lo So Te Z; Mateo et al., 2017).

La consideración de $H$. elisaeanum como especie quedó perfectamente aclarada en las monografías peninsulares (Mateo et al., 2017; Mateo et del Egido, 2017), un tratamiento que discrepa del tradicional de Zahn (1921), quien consideraba esta especie de origen híbrido, resultante del cruce entre $H$. candidum Scheele y $H$. laniferum Cav., especies que actualmente no comparten área (la primera pirenaica y la segunda de los Puertos de Beceite), muy diferentes entre sí y de H. elisaeanum (cf. Mateo et al., 2017).

\section{Hábitat y distribución geográfica}

Las plantas cordobesas de $H$. elisaeanum que se dan a conocer aquí proceden de las Sierras Subbéticas, al sur de la provincia, y su hallazgo constituye una novedad florística para la misma y también para la flora de Andalucía Occidental. Por otro lado, señalar que la existencia en la zona de hábitats altimontanos compatibles con esta especie abre la puerta a la posibilidad de que algunas de las conocidas en Andalucía Oriental puedan también alcanzar Córdoba $\mathrm{u}$ otras provincias occidentales andaluzas, como podría ser el caso de $H$. 
amplexicaule L., $H$. spathulatum Scheele $0 H$. aragonense Scheele.

\section{Bibliografía}

Blanca, G \& Cueto, M. (2011) Hieracium L. In G. Blanca et al. (Eds.) (2011). Flora vascular de Andalucía oriental. 2 $2^{\underline{a}}$ ed (1574-1576). Granada: Universidades de Almería, Granada, Jaén y Málaga.

Mateo, G. \& del Egido, F. (2017). Monografía de los géneros Hieracium y Pilosella en España. Jaca: Jolube Ed.

Mateo, G., Talavera, S. \& del Egido, F. (2017).
Hieracium L. In S. Talavera \& al. (Eds.) Flora iberica XVI(II) (pp. 1170-1258). Madrid: Departamento de publicaciones del CSIC.

Talavera, S. (1987) In B. Valdés et al. (Eds.) Flora de Andalucía occidental, 3 (98-99) Barcelona: Ketres Editora S. A.

Willkomm, M. (1893). Supplementum prodromi florae hispanicae. Stuttgart: Sumtibus E. Schweizerbart (E. Koch).

Zahn, K. (1921) Hieracium. In A. Engler (Ed.), Das Pflanzenreich. Regni vegetabilis conspectus, 75 (IV.280) (153-155). Leipzig: Verlag von Wilhem Engelmann. 